\title{
Penerapan Perluasan Teori Perilaku Berencana: Memahami Faktor yang Mempengaruhi Intensi Perilaku Tertib Lalu Lintas di Kalangan Mahasiswa
}

\author{
Ikhsan Fuady ${ }^{1}$, Maula Asri Ramadhani ${ }^{1}$, Adya Puspita ${ }^{1}$, Khilda Rosyidah ${ }^{1}$, Rama Noor \\ Dzalaludin $^{1}$
}

${ }^{1}$ Universitas Padjadjaran, Indonesia

\section{A R T I C L E I N F O}

Article history:

Received 23 Juni 2020

Accepted 16 Desember

2020

Available online 31

Desember 2020

Kata Kunci:

Intensi; Sikap; Norma

Sosial; Persepsi Resiko;

Tertib Lalu Lintas

\section{Keywords:}

Intention; Attitude; Social; Norms; Risk Perception; Orderly Traffic

\begin{abstract}
A B S T R A K
Tingginya angka kecelakaan lalu lintas di Indonesia tidak terlepas dari buruknya berilaku sebagian masyarakat dalam berdisiplin lalu lintas. Perilaku tertib lalu lintas merupakan perilaku yang penting dilakukan sebagai upaya pencegahan kecelakaan di jalan raya. Penelitian ini bertujuan untuk mengidentifikasi faktor faktor yang mempengaruhi intensi mahasiswa dalam berperilaku tertib lalu lintas dengan kerangka teori perilaku berencana. Metode penelitian ini didesain sebagai penelitian kuantitatif dengan metode survey. Populasi dan sampel penelitian ini adalah mahasiswa Pragram Studi Ilmu Komunikasi Unpad, dengan jumlah sampel 122 responden. Metode atau teknik sampling yang digunakan adalah simpel random sampling. Temuan penelitian ini adalah diketahui bahwa sikap mahasiswa tentang tertib lalu lintas, norma sosial memiliki pengaruh positif terhadap niat mahasiswa untuk berperilaku tertib di jalan raya. Sementara aspek persepsi resiko memiliki pengaruh negatif terhadap niat mahasiswa untuk berperilaku tertib di jalan raya.
\end{abstract}

A B S T R A C T

The high number of traffic accidents in Indonesia is inseparable from the poor behavior of some people in the discipline of traffic. Orderly traffic behavior is an important behavior carried out as an effort to prevent accidents on the highway. This study aims to identify the factors that influence students' intention to behave in an orderly manner within the framework of a theory of planned behavior. This research method is designed as a quantitative research with survey method. The population and sample of this study were students of Communication Studies Study Program Unpad, with a total sample of 122 respondents. The sampling method or technique used is simple random sampling. The findings of this study are known that student attitudes about traffic order, social norms have a positive influence on student intentions to behave in an orderly manner on the highway. While the aspect of risk perception has a negative influence on student intentions to behave in an orderly manner on the highway.

\footnotetext{
*orresponding author.

E-mail addresses: ikhsan.fuady@unpad.ac.id
} 



\section{Pendahuluan}

Angka kejadian kecelakaan di negara Indonesia tahun ke tahun terjadi peningkatan yang signifikan. Berdasarkan penelitian Anggarasena (2010: 84) Di Indonesia kejadian kecelakaan lalu lintas dapat dideskripsikan berdasarkan data selama 10 tahun terakhir menunjukkan bahwa kecelakaan lalu lintas di Indonesia menyebabkan rata-rata 10.000 kematian setiap tahunnya. Menurut data Mabes Polri, jumlah kecelakaan pada tahun 2019 mengalami peningkatan sebesar 3\% dibandingkan 107.500 kecelakaan pada tahun 2018 (Ardito 2019). Apandi (2013) mengemukakan bahwa KAPOLRI mencontohkan angka kecelakaan lalu lintas di Indonesia sudah mencapai tingkat yang mengkhawatirkan.Pada tahun 2019 angka kematian akibat lalu lintas mencapai 23.530. Jika dilakukan analisa kuantitatif maka angka kematian dalam satu bulan akan mencapai 1.960 yang setara dengan 63 orang meninggal dalam kecelakaan lalu lintas setiap hari. Antara Januari hingga Juni 2013, pelaku kecelakaan lalu lintas setiap hari mengalami 244 kecelakaan lalu lintas, bahkan 20\% diantaranya melibatkan remaja di bawah usia 16 tahun berstatus pelajar.

Banyaknya kecelakaan tidak lepas dari banyaknya pelanggaran lalu lintas yang dilakukan oleh pengguna jalan. Dibandingkan tahun 2018, jumlah pelanggaran lalu lintas pada tahun 2019 juga mengalami peningkatan, dengan 7.456.913 tiket dan 3.620 .393 pelanggaran yang berujung pada peringatan. Berdasarkan survey (Azka 2019) korban kecelakaan didominasi oleh pelajar dan mahasiswa. data Direktorat Penegakan Hukum Korps Lalu Lintas Polri mencatat terdapat 123.276 orang usia 15 tahun sampai 19 tahun menjadi korban kecelakaan lalu lintas pada tahun 2018.

Di Indonesia, peningkatan jumlah kendaraan bermotor dan human error setiap tahunnya merupakan salah satu faktor utama peningkatan kejadian kecelakaan lalu lintas. Rendahnya pemahaman masyarakat tentang peraturan lalu lintas dapat dilihat dari rendahnya disiplin mengemudi di masyarakat, sehingga terbentuk budaya disiplin di masyarakat. Semakin banyak pelanggaran lalu lintas (seperti pengendara sepeda motor) dapat melihat pemahaman dan pemahaman masyarakat tentang peraturan lalu lintas. Dilihat dari jumlah pelanggaran rambu lalu lintas di Bandung pada tahun 2014 tercatat sebanyak 39.205 kejadian. (Ardiansyah 2019).

Untuk meningkatkan kesadaran masayrakat dan mengurangi perilaku tidak tertib dalam berlalu lintas, diperlukan suatu strategi yyang tepat. Dalam mengembangkan strategi tersebut dibutuhkan landasan pengetahuan, fakktor yang mempengaruhi perilaku individu dalam tertib berkendara. Beberapa penelitian tentang tertib lalu lintas menunjukan bahwa kecelakaan yang sering terjadi diakibatkan oleh faktor perilaku manusia (Permana 2013), (Marsaid, Hidayat, and Ahsan 2013). Dalam memprediksi intensi perilaku untuk tertib lalu lintas, beberapa peneliti menggunakan kerangkan teori reason action dan juga teori plan behavior dari ajzen(Tunnicliff et al. 2012). (Moan 2013)mengungkapkan intensi individu dalam tertib mengendara dipengaruhi oleh sikap, norma sosial, dan persepsi perilaku individu. Sementara peneliti lain mengungkapkan sikap merupakan variabel terbaik dalam memprediksi intensi (Cristea and Delhomme 2016)(Iversen and Rundmo 2004),. (Tunnicliff et al. 2012) Sikap dan persepsi terhdap resiko memiliki pengaruh yang signifikan terhadap perilaku tertib lalu lintas. Beberapa menelitian menggungkapkan bahwa persepsi resiko merupakan variabel dominan yang mempengaruhi perilaku aman berkendara. Sementara itu beberapa peneliti menemukan bahwa persepsi control perilaku tidak memiliki pengaruh terhadap intensi (Kumphong et al. 2017).

Berdasarkan latar belakang di atas, pada penelitian ini peneliti ingin menguji teori perluasan perilaku berencana dengan menambahkan variabel persepsi resiko terhadap intensi mahasiswa dalam berkendara tertib lalu lintas. Tujuan penelitian ini adalah (1) menguji pengaruh Sikap terhadap Intensi mahasiswa dalam berkendara tertib lalu lintas, (2) Mengetahui pengaruh norma sosial terhadap intensi tertib lalu lintas, (3). Mengetahui pengaruh persepsi resiko terhadap intensi tertib lalu lintas.

\section{Metode}

Penelitian didesain dengan paradigma positifistik. Penelitian ini dilakukan dengan metode survei deskriptif explanatori. Menurut Kriyantono (2009) metode kuantitatif adalah penelitian yang mendeskripsikan atau menjelaskan masalah yang dapat meringkas hasil, sehingga 
digunakan metode penelitian survei. Penjelasan deskriptif menekankan hubungan kausal antara variabel penelitian dan pengujian hipotesis yang diajukan sebelumnya (Singarimbun \& Effendy 2013).Variabel variabel yang akan diteliti pada penelitian ini antara lain sikap, norma sosial, dan persepsi terhadap resiko sebagai variabel independen dan intensi perilaku sebagai variabel terikat.

Populasi penelitian ini adalah 680 mahasiswa program studi ilmu komunikasi Universitas Padjadjaran. Jumlah sampel diambil menggunakan surveysystem.com dengan Confidence Interval 7,5 pesen, sampel yang diambil sebanyak 137 responden. Pada penelitian ini terdapat sampel error sebanyak 15 responden, sehingga data yang dianalisis sebanyak 122 responden. Pengambilan sampel dilakukan dengan teknik sampling simpel randam sampling. Penelitian dilakukan mulai Maret 2020 hingga April 2020.

Untuk menjawab tujuan penelitian, analisis data dilakukan dengan uji statistika inferensi dengan uji regresi linier. Uji regresi merupakan uji statistika parametrik yang mensyaratkan data terdistribusi normal. Uji analisis regresi digunakan untuk membangun model. Jika nilai variabel $\mathrm{x}$ ditambah beberapa kali maka nilai variabel y dapat diprediksi. Dalam penelitian ini penulis menggunakan analisis regresi berganda. Persamaan regresi dapat digunakan untuk membuat fungsi/model garis lurus regresi. Persamaan dari analisis regresi dapat digambarkan sebagai berikut:

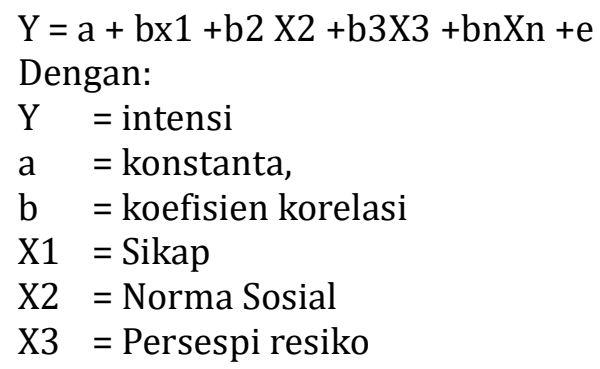

\section{Hasil dan pembahasan}

Tingginya angka kecelakaan lalu lintas sebagain besar disebabkan oleh perilaku pelanggaran dalam berlalu lintas. Berdasarkan hasil penelitian diketahui bahwa sebagain besar kejadian pelanggaran lalu lintas disebabkan oleh rendahnya kesadaran masyarakat. Persoalan lalu lintas di Indonesia secara umum mencakup sudut pandang keselamatan pengguna jalan, yang menjadikan masalah lalu lintas menjadi masalah yang harus segera diatasi mengingat keadaan saat ini, disiplin lalu lintas masyarakat masih sangat rendah. Faktor manusia, 6\% kendaraan, 5,5\% jalan dan 2,5\% lingkungan (terutama faktor manusia) mendominasi terjadinya kecelakaan terutama di kota-kota besar.Berdasarkan hasil temuan diungkapkan bahwa kecelakaan paling banyak dialami oleh pelajar dan mahasiswa . Mahasiswa merupakan generasi muda yang berpendidikan, seharusnya menjadi teladan dalam tertib berkendara. Penelitian ini dilakukan untuk mengungkapkan bagaiman sikap dn intensi perilaku mahasiswa dalam tertib berkendara. Menurut Fishbein dan Ajzen (1971) Perilaku pribadi akan dipengaruhi oleh pengetahuan, sikap, norma, dan pendapat sosial. Adanya pengetahuan tentang kepentingan objek akan membuat seseorang memiliki sikap terhadap sesuatu. Kemudian sikap tersebut mempengaruhi niat seseorang untuk melakukan suatu kegiatan. Aktivitas yang dilakukan disebut perilaku. Selain itu, sebagian besar perilaku biologis merupakan respons terhadap rangsangan eksternal.

\section{Sikap dan intensi mahasiswa dalam tertib berkendara}

Mahasiswa merupakan elemen masyarakat yag relatif aktif dalam mobilisasi. Sebagai bagaian dari masyarakat intelektual, semestinya mahasiswa memiliki sikap dan menampilkan contoh yang baik dalam tertib lalu lintas. Berdasarkan hasil analisis diketahui bahwa sikap mahasiswa dalam perilaku tertib lalu lintas digambarkan pada tabel 1 beikut; 
Tabel 1. Distribusi frekuensi sikap mahasiswa dalam tertib berkendara

\begin{tabular}{llll}
\hline NO & $\begin{array}{l}\text { Sikap Mahasiswa Dalam Tidakan } \\
\text { Tertib Berkendara }\end{array}$ & frekuensi & $\begin{array}{l}\text { Persentase } \\
(\%)\end{array}$ \\
\hline 1 & Sangat tinggi & 61 & 50 \\
\hline 2 & Tinggi & 46 & 37,7 \\
\hline 3 & Rendah & 0 & 0 \\
\hline 4 & Sangat Rendah & 15 & 12,3 \\
\hline
\end{tabular}

Sumber: analisis data primer

Dari Tabel 1 diketahui bahawa secara umum sikap mahsiswa terhadap tertib lalu lintas terkategori tinggi, dimana sikap yang tinggi dan sangat tinggi mencapai angka 85,7 persen. Ha ini menunjukakan bahwa sebagaian besar mahasiswa relatif memiliki sikap yang baik. Akan tetapi berdasarkan hasil analisis iini, masih ada mahsiswa yang memiliki sikap yang buruk dalam tertib lalu lintas. Berdaskan temuan ini, para stakeholder perlu memberikan perhatian khusus baik dengan melakukan sosialisasi ataupun bentuk edukasi lainnya dalam usaha meningkatkan sikap mahasiswa tertib dalam berlalu lintas.

Intensi merupakan niat individu yang mendorong untuk bertindak. Perilaku tertib dalam berkendara, didorong oleh adanya intensi individu. Berdasarkan hasil analaisis intensi mahasiswa dlam berperilaku tertib berkendara digambarkan pada Tabel 2 .

Tabel 2. Distribusi frekuensi intensimahasiswa dalam tertib berkendara

\begin{tabular}{llll}
\hline NO & $\begin{array}{l}\text { Perilaku Tertib Berkendara Pada } \\
\text { Mahasiswa }\end{array}$ & frekuensi & $\begin{array}{l}\text { Persentase } \\
(\%)\end{array}$ \\
\hline 1 & Sangat tinggi & 64 & 52,5 \\
\hline 2 & Tinggi & 30 & 24,6 \\
\hline 3 & Rendah & 27 & 22,1 \\
\hline 4 & Sangat Rendah & 1 & 0,8 \\
\hline
\end{tabular}

Sumber: analisis data primer

Pada Tabel 2 digambarkan bahawa secara umum intensi mahasiswa terhadap tertib lalu lintas terkategori tinggi, dimana intensi yang tinggi dan sangat tinggi mencapai angka 77,1 persen. Ha ini menunjukakan bahwa sebagaian besar mahasiswa relatif memiliki intensi yang baik. Akan tetapi berdasarkan hasil analisis ini, masih ada mahasiswa yang memiliki intensi yang buruk dalam tertib lalu lintas. Berdasakan temuan ini, para stakeholder perlu memberikan perhatian khusus baik dengan melakukan sosialisasi ataupun bentuk edukasi lainnya dalam usaha meningkatkan sikap mahasiswa tertib dalam berlalu lintas.

\section{Faktor Yang Mempengaruhi Intensi Perilaku Tertib Lalu Lintas Di Kalangan Mahasiswa}

Untuk menguji faktor faktor yang mempengaruhi intensi perilaku tertib lalu lintas, penelitian ini melakukan pengujian teori perilaku berencana dalam tertib lalu lintas. Untuk memahami faktor yang mempengaruhi Intensi Perilaku Tertib Lalu lintas di Kalangan Mahasiswa, penelitian ini mengunakan uji parametrik multivariat dengan regresi linier berganda. Berdasarkan hasil analisis dengan menggunakan software SPSS for windows, kelayakan model dapat digambarkan pada Tabel 3.

Tabel 3. Summary Model dan Anova regresi berganda faktor yang mempengaruhi intesi

\begin{tabular}{lllllll}
\hline Model & $\mathrm{R}$ & $\mathrm{R}$ & $\begin{array}{l}\text { Std. } \\
\text { Square }\end{array}$ & $\begin{array}{l}\text { Error of } \\
\text { the } \\
\text { Estimate }\end{array}$ \\
\hline 1 & $.521^{\text {a }}$ & .271 & F & & Sig. \\
\multicolumn{6}{c}{ Sumber: Analisis data primer }
\end{tabular}


Berdasarkan tabel di atas diketahui bahwa intensi perilaku tertib lalu lintas dipengaruhi oleh variabel variabel dependennya secara bersamaan. Hail ini dapat diketahi dari niali $F_{\text {hit }}>$ dari $F$ tabel, atau nilasi signifikansinya lebih kecil dari 0,05. Selain itu ketiga variabel ini dapat menjelaskan intensi mahasiswa dalam tertib mengendara pada lalu lintas sebesar 27,1 persen. Penelitian ini dengan menambahkan variabel persepsi terhadap resiko memberkuat dari beberapa penelitian sebelumnya yang mengambil kerangka teori tindakan berencana(Moan 2013). Dari hasil analsis ini diketahui bahwa perilaku mahasiswa dalam tertib berlalu lintas didorong secara bersama sama oleh variabel sikap mahasiswa, sosial norma atau dukungan sosial dari lingkungan terdekat serta persepsi terhadap resiko kecelakaan. Berdasarkan uji parsial lanjutan, faktor faktor yang mempengaruhi intensi mahsiswa dalam berperilaku tertib lalu lintas dapat digambarkan pada Tabel 4.

Tabel 4. Model, coefisien, dan uji T regresi berganda faktor yang mempengaruhi intesi

\begin{tabular}{|c|c|c|c|c|c|}
\hline \multirow{2}{*}{ Model } & & \multicolumn{2}{|c|}{$\begin{array}{c}\text { Unstandardized } \\
\text { Coefficients }\end{array}$} & \multirow{2}{*}{$\mathrm{t}$} & \multirow{2}{*}{ Sig. } \\
\hline & & B & $\begin{array}{l}\text { Std. } \\
\text { Error }\end{array}$ & & \\
\hline \multirow{4}{*}{1} & (Constant) & 4.649 & 1.495 & 3.11 & 0.002 \\
\hline & ATT & 0.44 & 0.159 & 2.759 & 0.007 \\
\hline & SN & 0.353 & 0.082 & 4.305 & 0.000 \\
\hline & $\mathrm{RP}$ & -0.163 & 0.074 & $\begin{array}{r}- \\
2.19 \\
9\end{array}$ & 0.03 \\
\hline
\end{tabular}

a. Dependent Variable: ITT

Sumber: analsis data primer

Berdasarkan tabel di atas maka fungsi atau persamaan regresi linier di gambarkan pada persamaaan berikut;

$Y=4,649+0,44 \mathrm{X} 1+0,353 \mathrm{X} 2-0,163 \mathrm{X} 3+\mathrm{e}$

Pada hasil uji t tabel 3 ini diketahui bahwa sikap memiliki pengaruh yang kuat terhadap intensi mahasiswa dalam melakukan perilaku tertib lalu lintas, dengan koefisien 0,44 dan signifikansi lebih kecil dari 0,05 atau nilai $t_{\text {hit }}$ lebih besar dari $t_{\text {tabel. }}$. Hal ini menunjukan bahwa Perilaku mahasiswa untuk tidak melanggar tataterlib lalu lintas dipengaruhi oleh pandangan dan keyakinan dirinya. Azjen dalam konsep teori perilaku berencana mengungkapkan sikap merupakan keyakianan dan evaluasi terhadap objek tertentu dalam hal ini perilaku tertib lalu lintas. Keyakinan mahasiswa yang baik tentang pentingnya tertib lalu lintas dalam mengurangi terjadinya kecelakaan lalu lintas yang dapat merugikan diri sendiri dan orang lain akan mempengaruhi kuat untuk tidak melakikan pelanggaran. Sementara itu sikap yang buruk berpenagruh secara nyata pada mahsiswa untuk berperilaku tidak tertib dalam mengendarai kendaraan. Penelitian inimendukung dari beberapa hasil penelitian serupa yang menggungkapkan peran kuat sikap terhadap intensi,(Iversen and Rundmo 2004).

Norma sosial merupakan kebiasaan umum dan menjadi patokan bagi kelompok masyarakat dan batas wilayah tertentu. Norma sosial dalam teori tindakan berencana merupakan dukungan lingkungan sosial terdekat terhadap perilaku tertentu. Norma sosial pada penelitian ini adalah dukungan orang tua, teman dekat serta lingkungan sekitar terhadap perilaku tertib berkendara. Berdasarkan hasil analisis diketahui cukup bukti yang kuat untuk mengatakan bahwa intensi perilaku mahasiswa dalam melakukan tertib lalu lintas dipengruhi 
oleh norma sosial yang ada di masyarakat. Hal ini diketahui dari nilai signifikansi lebih kecil dari 0,01 dan koefisien korelasi sebesar 0,353. Ini menunjukan bahwa peningkatan dukungsan sosial sebesar satu satuan dapat meningkatkan intensi tertib berkendara sebesar 0,353 satuan.

Dalam upaya meningkatkan intensi perilaku lalu lintas yang semakin baik dikalangan mahasiswa, perlunya suatu usaha penguatan norma sosial baik dalam lingkungan keluarga, kampus, ataupun pihak kepolisian dan lingkungan sekitar pada umumnya. Penguatan dalam lingkungan keluarga misalnya pembiasaan penggunaan keselamatan setiapa akan berkendara. Sementara dari lingkungan sekitar seperti kampus ataupun fihak kepolisian dalam melakukan edukasi atau pembudayaan secara rutin dalam tertib berkendara. Peningkatan ini tentu akan berdampak positif perubahan berilaku mahasiswa dalam berkendara.

Persepsi resiko merupakan pandangan atau penilaian terhadap situasi risiko yang didasarkan pada pengalaman atau keyakinan yang dimiliki. Dalam konteks penelitian ini persepsi resiko perupakan penilaian mahasiswa terhadap perilaku tertib berkendara seperti menggunaan helm dalam kendaraan bermotor atau sabuk pengaman dalam berkendara mobil dan kelengkapan lainnya. Dalam konteks konsep persepsi resiko berkebalikan dengan konsep persepsi keamanan.

Berdasarkan Tabel 4 diketahui memiliki cukup bukti untuk mengatakan bahwa persepsi resiko terhadap perilaku melanggar peraturan lalu lintas memiliki pengaruh terbalik terhadap intensi. Hal ini diketahui dari nilai nilai signifikansi lebih kecil dari 0,01 dan koefisien korelasi sebesar -0,163. Semakin ting persepsi resiko menyebabkan semakin tidak ingin melakukan pelanggaran terhadap lalu lintas.

Dari hasil analisis ini diketahui adanya pengaruh persepsi resiko terhadap intensi tertib lalu lintas. Persepsi resiko resiko yang tinggi cenderung mengakibatkan rendahnya perilaku tidak tertib (seperti ugal ugalan berkendara), tidak menggunakan safety dan lainnya. Sehingga untuk meningkatkan tertib lalu lintas diperlukan peningkatan persepsi terhadap resiko. Persepsi terhadap resiko beberapa penelitian menunjukan bahwa sangat dipengaruhi oleh efektfitas komunikasi resiko(Sawant and Sansgiry 2018). Yoo (2019) mengungapkan bahwa terpaan informasi pada sosial media dapat meningkatkan persepsi resiko. Dalam upaya peningkatan perilaku tertib berkendara stakeholder dapat mengambil peran dengan berbagai bentuk kegiatan komunikasi, baik komunikasi interpersonal maupun bermedia.

\section{Simpulan dan saran}

Tertib dalam berlalu lintas merupakan suatu hal yang perlu dikedepandalan di jalan raya, sebagai upaya mengurangi resiko kecelakaan lalu lintas. Mahasiswa merupakan elemen masyarakat berbendidikan diharapkan memiliki keteladanan dalam berlalu lintas. Berdasarkan hasil penelitian, sikap dan intensi mahasiswa dalam berlalu litas terkategori tinggi, meskipun masih ada sebagian kecil mahasiswa yang terkategori rendah. Faktor faktor yang mempengaruhi intensi mahasiswa dalam tertib berlalu lintas adalah aspek sikap dan sosial yang memiliki pengaruh positif terhadap intensi mahsiswa dalam tertib berkendara. Untuk variabel persepsi resiko memiliki pengaruh signifkan yang bersifat negatif. Sehingga peningkatan persepsi resiko perpengaruh terhadap penurunan perilaku ugal ugalan atau tidak tertib dalam berlalu lintas. Untuk meningkatkan perilaku tertib lalu lintas diperlukan upaya semua staeholder dalam mendorong peningkatan faktor faktor yang mempengaruhi perilaku tertib dalam berlalu lintas. Berbagai bentuk usaha tersebut dapat dilakukan dengan edukasi, sosialisasi baik dimedia, amupun komunikasi interpersonal. Kegiatan lain yang dapat neingkatkan perilaku tertib lalu lintas adalah penguatan norma sosial yang dimulai dari lingkungan keluarga, kampus dan masyarakat sekitar.

\section{Daftar Rujukan}

Anggarasena, B. 2010. "Strategi Penegakan Hukum Dalam Rangka Meningkatkan Keselamatan Lalu Lintas Dan Mewujudkan Masyarakat Patuh Hukum.” Tesis Undip. 
Ardiansyah, Novian.2019. Mahasiswa dan Pelajar Dominasi Kecelakaan Lalu Lintas Saat Berkendara Motor.tribunnews.com.28Januari2019. https://jakarta.tribunnews.com/2019/01/28/mahasiswa-dan-pelajar.

Azka, Rinaldi Mohammad.2019. Survei Menunjukkan Korban Kecelakaan Lalu Lintas Didominasi Pelajar.Kontan.com.25september2019.https://ekonomi.bisnis.com/read/20190925/98/1 152186/survei-menunjukkan-korban-kecelakaan-lalu-lintas-didominasi-pelajar

Cristea, Mioara, and Patricia Delhomme. 2016. "The Effects of Co-Presence on Risk Perception and Intention to Engage in Risky Behaviors." Journal of Safety Research 56: 97-103. https://doi.org/10.1016/j.jsr.2015.12.006.

Iversen, Hilde, and Torbjørn Rundmo. 2004. "Attitudes towards Traffic Safety, Driving Behaviour and Accident Involvement among the Norwegian Public." Ergonomics 47 (5): 555-72. https://doi.org/10.1080/00140130410001658709.

Kriyantono 2009, Rachmat, Teknik Praktis Riset Komunikasi (disertai Contoh Praktis Riset Media Public Relations, Advertising, Komunikasi Organisasi, Komunikasi Pemasaran), Edisi ke-3, Kencana Prenada Media Group, Jakarta,

Kumphong, Jetsada, Thaned Satiennam, Wichuda Satiennam, and Wichuda Satiennam C. 2017. "A Study of Social Norms and Motorcycle Helmet Use Intentions among Student Riders in University: A Comparison of the Theory of Reasoned Action and the Theory of Planned Behavior Automatic System for Road Safety View Project A Study of Social Norms and Mot." Proceedings of the Eastern Asia Society for Transportation Studies, no. 2016. https://www.researchgate.net/publication/325010258.

Marsaid, M Hidayat, and Ahsan. 2013. "Lalu Lintas Pada Pengendara Sepeda Motor Di Wilayah Polres." Jurnal Ilmu Keperawatan $1 \quad$ (2): 98-112. https://doi.org/http://dx.doi.org/10.11606/issn.2176-7262.v49i5p475-482.

Moan, Inger Synnøve. 2013. "Whether or Not to Ride with an Intoxicated Driver: Predicting Intentions Using an Extended Version of the Theory of Planned Behaviour." Transportation Research Part F: Traffic Psychology and Behaviour 20 (1369): 193-205. https://doi.org/10.1016/j.trf.2013.08.001.

Permana, Bambang Eka. 2013. Faktor Penyebab Pelanggaran Lalu Lintas Oleh Pengendara Sepeda Motor Di Kota Kuningan.

Ramadhan, Ardito. 2019. Polri Sebut Jumlah Kecelakaan Lalu Lintas Meningkat pada 2019.kompas.com.29.Desember2019.,https://nasional.kompas.com/read/2019/12/28/10 355741/polri-sebut-jumlah-kecelakaan-lalu-lintas-meningkat-pada-2019

Sawant, Ruta, and Sujit Sansgiry. 2018. "Communicating Risk of Medication Side-Effects: Role of Communication Format on Risk Perception." Pharmacy Practice 16 (2): 1-8. https://doi.org/10.18549/PharmPract.2018.02.1174.

Singarimbun, Masri dkk, (1989), Metode Penelitian Survei 2013 (Edisi Revisi), Penerbit Pustaka LP3ES, Jakarta,

Tunnicliff, Deborah J., Barry C. Watson, Katherine M. White, Melissa K. Hyde, Cynthia C. Schonfeld, and Darren E. Wishart. 2012. "Understanding the Factors Influencing Safe and Unsafe Motorcycle Rider Intentions." Accident Analysis and Prevention 49: 133-41. https://doi.org/10.1016/j.aap.2011.03.012.

Yoo, Woohyun. 2019. "How Risk Communication via Facebook and Twitter Shapes Behavioral Intentions: The Case of Fine Dust Pollution in South Korea." Journal of Health Communication 24 (7-8): 663-73. https://doi.org/10.1080/10810730.2019.1655607. 